\title{
Uma nova política exterior depois do apartheid? - Reflexões sobre as relações regionais da África do Sul, 1974 - 1998
}

\author{
WOLFGANG DÖPCKE*
}

I.

A partir de 1989, o subcontinente sul-africano, até então uma das principais regiões mundiais de conflito, passou por um processo de mudanças que o transformou em uma zona de paz entre os Estados. Com a exceção da guerra civil em Angola, todas as principais ameaças à segurança regional haviam sido eliminadas, e, conseqüentemente, a região começou a gozar de uma situação de segurança interestatal desconhecida há mais de uma geração.

Esta transformação em um ambiente regional mais pacífico se deu passo a passo. Começou com a retirada das tropas sul-africanas de Angola e a solução do conflito sobre a Namíbia em 1988, seguida pelas eleições livres e pela independência deste país em 1990. Ao mesmo tempo, a África do Sul iniciou um processo de redefinição de sua política regional, despedindo-se efetivamente da desestabilização e da política das guerras não-declaradas contra os seus vizinhos, que tanto caracterizaram a Total National Strategy dos anos 80. A partir de 1990, a própria África do Sul realizou um processo de reformas internas, chegando a extinguir o regime do apartheid, acompanhado por um profundo realinhamento da inserção regional e mundial do país. Já em 1993, foram eliminadas quase todas as sanções contra o antigo paria da comunidade internacional.

A próxima etapa do processo de normalização das relações regionais foi a solução da guerra civil em Moçambique, que havia envolvido, direta ou indiretamente, todos os Estados vizinhos. Em outubro de 1994, eleições foram realizadas com êxito, colocando um ponto final na tradição do conflito armado que havia dominado a realidade deste país desde o início da luta armada contra o colonialismo português nos anos 60 .

* Professor Adjunto de História Contemporânea da Universidade de Brasília. 
Os eventos em Angola destoam desta imagem geral de pacificação. No conflito angolano, mediações levaram à conclusão do Acordo de Paz de Bicesse, em 1991, entre o Governo angolano e a UNITA e às eleições multipartidárias em setembro de 1992. Mas, a recusa, por parte da UNITA, em aceitar a derrota eleitoral, bem como a sua decisão de reiniciar a guerra, reabriram este conflito, agora em uma escala muito superior. A UNITA chegou a controlar uma grande parte do território angolano, mas perdeu a iniciativa militar ao final de 1994. Com a perda da maior parte do seu apoio externo, o movimento iniciou então uma dramática retirada. O último golpe contra a capacidade militar deste movimento se deu em maio de 1997, com a queda do regime de Mobuto no Zaire, o último aliado da UNITA na África Austral. A UNITA sofreu uma série de derrotas militares e, desde o final de 1994, as hostilidades se reduziram a uma pequena escala. Ao mesmo tempo, negociações sobre uma solução pacífica do conflito foram reiniciadas e perduram até hoje em dia.

Existem duas razões interligadas que explicam esta pacificação das relações regionais na África Austral durante os últimos 10 anos:

a) o fim da Guerra Fria e, subseqüentemente, do engajamento conflituoso da duas super-potências no sub-continente sul-africano e

b) o fim da política de desestabilização da África do Sul.

Este artigo pretende analisar a transformação das relações regionais através da perspectiva de um dos atores principais, isto é, da África do Sul e sua política regional. Pretende demonstrar que as mudanças principais no processo de inserção regional da África do Sul aconteceram entre 1989 e 1992-3 e, assim, antes da posse, em 1994, do novo Governo de National Union, liderado pelo Congresso Nacional Africano (CNA). Em segundo lugar, será demonstrada a maneira pela qual os dois fios condutores da política exterior da África do Sul, a política oficial do Estado do apartheid e a "contra-política" do CNA se fundiram entre 1991 e 1994. Durante esta fusão, conceitos e princípios importantes do CNA foram abandonados. Apesar da garantia enfática dada por parte do CNA de que a África do Sul abandonaria todas as ambições hegemônicas sub-regionais, a política de "geo-economia” continuou a influenciar profundamente a política regional do país depois de 1994. Nesta perspectiva "geo-econômica", o sub-continente representa principalmente um mercado para a África do Sul e, conseqüentemente, as relações entre os Estados chegam a ser influenciadas, cada vez mais, por interesses econômicos conflituosos que, às vezes, têm uma longa "pré-história”anterior à Segunda Guerra Mundial.

\section{II.}

As relações internacionais da África Austral não foram sempre tão conflituosas como na década de 80. Desde a ocupação colonial da região, a subjugação da população indígena e a repressão da resistência contra a dominação 
estrangeira em torno do final do século XIX, a África do Sul gozou de um longo período de paz (colonial), que só foi interrompido pela Guerra Sul-Africana de 1899-1902 e pela ocupação por tropas sul-africanas da Deutsch-Südwest-Africa (Namíbia), no início da Primeira Guerra Mundial.

Historicamente, a divisão colonial da África Austral reflete a competição entre o imperialismo britânico e o "sub-imperialismo" dos boêres, mas é também resultado das conquistas territoriais dos ingleses para conter as ambições expansionistas da Alemanha e de Portugal durante a época da "Corrida pela África”. Depois da fundação da União da África do Sul em 1910, um aspecto básico da política regional deste Estado, além da penetração econômica das colônias vizinhas, foram as tentativas de incorporação do território ao norte de Limpopo. Estes esquemas incluíram o desenho do General Smuts de uma União Maior ("Greater Union”), reunindo partes da África Austral até o Norte de Moçambique e de Angola à União, a tentativa frustada de incorporar a Rodésia do Sul em 1923 e a igualmente frustrada política de anexação dos Territórios do Alto Comissário (High Commissioner's Territories $)^{1}$. O imperialismo inglês conseguiu conter esta política expansionista da África do Sul, com a notável exceção do caso da Namíbia. ${ }^{2}$ Apesar da suave política de containment por parte da Grã-Bretanha, o ambiente regional da África do Sul foi amigável até a Segunda Guerra Mundial, e não representava nenhuma ameaça ao que era considerado segurança do Estado. Os vizinhos da África do Sul não só se consistiam em Estados coloniais, com os mesmos problemas de legitimidade perante a população negra, mas eles tinham também herdado muitas instituições de hegemonia dos colonos brancos, inclusive a convicção da supremacia branca como razão e justificativa principal do projeto colonial no continente negro.

Desde a chamada “revolução mineral”, a África do Sul surgiu, pelo menos em termos econômicos, como potência regional hegemônica. O desenvolvimento significativo da indústria de minérios, desde o último quartel do século XIX, transformou a economia daquele país. A África do Sul, que antes sobrevivia de um setor agro-exportador atrasado, passou a ser um dos principais produtores de ouro no mundo e, subseqüentemente, estabeleceu a indústria secundária mais desenvolvida no continente africano. Atraiu, assim, expressivo investimento de capital estrangeiro e muita imigração da Europa. Respondendo às necessidades e aos interesses desta economia diversificada, a África do Sul reestruturou as relações com os seus vizinhos e, em consequência, foi o ator mais dinâmico nas relações regionais do sub-continente desde a época da fundação da União Sul-africana em 1910 até os anos 60. Surgiu assim o que os pesquisadores chamaram de um "subordinate state system"3 . A África do Sul se tornou um "gigante econômico" em relação aos seus vizinhos, bem como à África negra. Em 1980, o produto nacional bruto da África do Sul foi três vezes superior ao total dos outros países da SADCC (Southern African Development Coordination Conference) ${ }^{4}$. Em 1995, 
embora tivesse apenas 8\% da população total, a África do Sul representava 48\% do produto nacional bruto de toda a África ao sul do Saara.

A interação econômica entre a África do Sul e os seus vizinhos não aconteceu de forma igualitária. Pelo contrário: histórica e atualmente, este país domina esta relação. No discurso acadêmico, a África do Sul é caracterizada como "hegemônica"5, "sub-imperial"6 ou "potência semi-periférica"7 . Grundy identifica um "imperialismo sul-africano" que visa exercer hegemonia no sub-sistema da África Austral. ${ }^{8}$ O intercâmbio na região é caracterizado como "colonial”, destacando-se o fato de que a África do Sul considera os países vizinhos como “mercado natural” para os produtos de sua indústria secundária. Por outro lado, o termo amplamente usado para caracterizar a situação dos Estados vizinhos em relação à África do Sul, é dependência. ${ }^{9}$ Nos anos 80, o grau de dependência para com a África do Sul variava muito entre os Estados individuais: de dependência e vulnerabilidade absoluta (no caso dos BSL-states ${ }^{10}$ e Namíbia), dependência média (Zimbábue, Moçambique, Zâmbia) até dependência relativamente baixa (Angola). ${ }^{11}$ É importante ressaltar que, embora a hegemonia sul-africana seja substantiva, uma dependência absoluta não é, ou era, a regra. "Much in the region works in favour of South Africa”, argumenta du Pisani, "but South Africa's regional hegemony is not without limitations." 12

Este ambiente regional amigável para a África do Sul começou a mudar depois de 1945, primeiramente em nível mundial e, depois, na sub-região. Enquanto, depois da Guerra, o mundo entrou no seu último ciclo de descolonização e também guardou, de certa forma, o anti-racismo da guerra contra Hitler como patrimônio ideológico, na África do Sul culminou a discriminação racial com a realização do programa de apartheid do Partido Nacional, que chegou ao poder em 1948.

Entre 1948 e 1960, a África do Sul surgiu como "paria internacional”. ${ }^{13}$ Durante este período, a preservação e a defesa do sistema de apartheid representavam o objetivo principal e quase único da política exterior da África do Sul. Na arena internacional, a África do Sul tentou, inicialmente com grande sucesso, vincular sua ordem interna às divisões da Guerra Fria e se projetou como defensora não somente dos supostos valores da civilização branca no continente negro, mas também como fiel bastião contra o comunismo e a suposta expansão soviética. Em termos regionais, “...successive South African Governments made the creation of a stable regional milieu favorable to South Africa's economic and security interests a priority goal of foreign policy”. ${ }^{14}$ Desde os anos 50, a política regional da África do Sul é reativa e defensiva, apesar do seu caráter ofensivo e dos seus, às vezes espetaculares, sucessos a curto prazo. Ela reagiu a desafios que, na perspectiva do regime governante, tornavam-se cada vez mais ameaçadores. ${ }^{15}$

A resposta inicial ao ambiente internacional crescentemente hostil e ao nacionalismo africano cada vez mais forte consistiu internamente na intensificação da política do apartheid. Regionalmente, a política da África do Sul caracterizou- 
se pelas tentativas bem determinadas de incorporação dos Territórios do Alto Comissário Britânico e da Namíbia. Todavia, embora somente tenha obtido sucesso temporário no último caso, as independências de Suazilândia, Lesoto e Botsuana, nos anos 60, não se transformaram numa ameaça à segurança do regime do apartheid como era temido pelo etablissement branco. Do início dos anos 60 até a metade dos anos 70, a África do Sul seguiu uma política regional que du Pisani chamou de "assertive incorporation". A África do Sul buscou um rapprochement com os países africanos independentes, usando seu potencial econômico para mantêlos dóceis e estabelecer relações mais próximas. A variante mais conceituada deste outward movement foi o conceito do Primeiro Ministro Vorster de um mercado comum dos Estados da África Austral. ${ }^{16}$

O colapso do colonialismo português na África, seguindo a derrubada do regime salazarista em abril de 1974, afetou dramaticamente o balanço de poder na África Austral. A reação inicial da África do Sul à destruição do seu cordon sanitaire contra a África negra foi "cooly statemanlike" ${ }^{17}$, pelo menos em relação à indendência de Moçambique. A exposição das fronteiras da África do Sul e da Namíbia a Estados que adotavam potencialmente políticas anti-apartheid, e o quase encercamento da Rodésia do Sul por Estados da Linha de Frente ${ }^{18}$, provocou Pretória a apresentar uma nova iniciativa na política regional, a chamada détente, que governou as relações internacionais na África Austral entre meados de abril de 1974 e o final de 1975.

O raciocínio central desta abordagem foi o de que a nova situação de segurança da África do Sul necessitava uma resolução pacífica dos conflitos correntes na África Austral (Namíbia e Rodésia do Sul), senão os conflitos iriam se escalar. Conseqüentemente, os movimentos anti-coloniais poderiam se radicalizar e a maioria dos africanos chegaria a apoiar estes movimentos radicais e "comunistas“. Iniciou-se, assim, uma intensa diplomacia em torno do impasse constitucional na Rodésia, envolvendo principalmente a África do Sul e a Zâmbia. Reagiram também positivamente ao rapprochement do regime do apartheid a Costa do Marfim e a Libéria. Pretória exerceu certa pressão sob o regime branco de Ian Smith para que um governo majoritário africano fosse aceito, mas mostrou menos determinação no caso do Estado da Namíbia, ilegalmente por ela mesma ocupado. O apogeu da diplomacia de détente foi o memorável encontro, no dia 25 de agosto de 1975, na ponte sob o rio Zambezi em Victoria Falls, entre Ian Smith, os líderes dos movimentos guerrilheiros de Zimbábue, o Presidente Vorster e o Presidente de Zâmbia, Kenneth Kaunda. A détente falhou dramaticamente, sobretudo em função da recusa de Ian Smith em considerar a participação africana no processo político na Rodésia, por causa das divisões graves e das rivalidades entre os movimentos de libertação de Zimbábue, e dentro deles, por causa da inflexibilidade da África do Sul na questão da Namíbia e da discreção das potências ocidentais em assumir um papel mais determinado nas negociações. Mas a détente 
recebeu o golpe mortal da própria África do Sul, devido ao envolvimento do país na guerra civil em Angola, que culminou com a invasão sul-africana maciça e aberta entre setembro/outubro de 1975 e janeiro de $1976 .{ }^{19}$

A intervenção militar na guerra civil em Angola provocou uma virada na política regional da África do Sul. ${ }^{20}$ Embora, antes da invasão, a África do Sul houvesse clandestinamente cooperado com Portugal no combate a movimentos guerrilheiros, atravessado a fronteira com Angola na perseguição a combatentes da SWAPO $^{21}$ e, ainda, na Rodésia, tivesse também auxiliado Ian Smith com o envio de uma tropa de polícia para-militar, até então nunca havia abertamente intervido com força militar na política interna dos seus vizinhos. A intervenção em Angola fundou, pois, uma tradição de interferência repressiva no sub-continente que, durante a era de desestabilização da Total National Strategy nos anos 80, assumiu caráter sistemático.

Observadores argumentam que a intervenção sul-africana, ao lado da FNLA e da UNITA ${ }^{22}$, representava uma decisão ad-hoc e não seguia um claro e estrito planejamento político e estratégico. ${ }^{23}$ A decisão se baseou na percepção, principalmente por parte da inteligência militar, de que um governo angolano do MPLA ameaçaria os interesses de segurança da África do Sul na Namíbia, porque certamente apoiaria o movimento de libertação daquele país, a SWAPO. Nesta invasão, a África do Sul não utilizou o seu inteiro potencial militar, obviamente em função de suposições equivocadas sobre a fragilidade do MPLA, e o poderio da FNLA e da UNITA. Além disto, a África do Sul gravemente subestimou a determinação por parte da União Soviética e de Cuba de ajudar o MPLA. Segundo Grundy, o engajamento militar somente moderado refletia também uma disputa de orientação na política regional no centro do poder na África do Sul e mostrava "the compromise character of the decision and the conduct of the intervention, by which the hawks [principalmente o $S A D F$, W.D.] secured the decision to attack provided the doves [os "políticos" e o DFA, W.D.] were mollified by a less intensive and extensive SADF deployment."24

A África do Sul parecia esperar por um envolvimento maçico e solidário por parte dos EUA, como muitos observadores alegam. Marte e outros argumentam convincentemente que o objetivo principal teria sido "to forge a formal Cold War alliance with the US, which was to serve as a smoke screen for maintaining white dominance in southern Africa." 25 Tudo indica que os EUA tinham conhecimento anterior da invasão e talvez tenham até participado ativamente na preparação, embora o então Secretário de Estado, Henry Kissinger, sempre, e firmemente, tenha negado ser verdadeira esta alegação. ${ }^{26}$ Entretanto, ficou demonstrado que a avaliação sul-africana sobre o relativo poder de cada lado na guerra civil angolana, e sobre a disposição dos EUA de arriscar mais um aberto engajamento num conflito no Terceiro Mundo, logo depois do desastre da Guerra do Vietnam, era equivocada. Diante da possibilidade de ter que enfrentar uma guerra semi-convencional 
prolongada, apenas com as enfraquecidas UNITA e FNLA como aliadas, e, provavelmente, contra soldados cubanos equipados com tecnologia militar soviética, a África do Sul optou por uma rápida retirada em janeiro de 1976. A África do Sul sofreu uma experiência traumática em Angola, lutando pela primeira vez numa guerra africana e não conseguindo alcançar nenhum dos seus objetivos. Sentiu-se então profundamente traída pelo Ocidente, cuja "batalha contra o comunismo" a África do Sul proclamava estar lutando.

Em 1980, o cordon sanitaire de colônias brancas, protegendo a África do Sul da "onda negra”, finalmente se despedaçou. Depois de Angola e Moçambique, a Rodésia do Sul "caiu" e se tornou independente, com o governo do "marxista" Robert Mugabe, sob o nome de Zimbábue. A vitória nas eleições de fevereiromarço de 1980 de R. Mugabe, e do seu partido ZANU-PF ${ }^{27}$, mostrou, mais uma vez, um erro de cálculo por parte da assessoria estratégica da África do Sul. A guerra de libertação de Zimbábue ganhou enorme fôlego com a independência de Moçambique em 1975, expondo, assim, a Rodésia do Sul à infiltração de guerrilheiros ao longo de mais de 1.000 quilômetros de fronteira com Moçambique. A África do Sul investiu pesadamente na chamada "solução interna" e no seu candidato, Bishoph Abel Muzorewa, que foi inventado por Ian Smith como último salvaguarda na tentativa de exclusão do poder no país dos dois movimentos de libertação (ZANU e ZAPU). Quando as eleições “internas” em 1979 nem satisfizeram a comunidade internacional, nem pacificaram o país, e a reunião da cúpula dos países do Commonwealth obrigou a Primeira Ministra da Grã-Bretanha, M. Thatcher, a concordar com a convocação de uma conferência constitucional, incluindo os dois movimentos, a África do Sul jogou o seu peso, sobretudo financeiro (mais clandestina do que abertamente), novamente atrás de Muzorewa. Nas eleições livres de 1980, finalmente, o Bishoph ganhou 3 das 100 cadeiras do parlamento e o encercamento da África do Sul, por Estados hostis à política do apartheid e simpáticos aos objetivos do CNA, se completou na sua fronteira ao norte.

Este colapso das colônias brancas em torno da África do Sul foi seguido por uma explosão da resistência interna, iniciando-se com a revolta de SOWETO em 1976, provocando assim uma severa crise no país e uma reação externa drástica na forma de um embargo de armas, pronunciado pelas Nações Unidas. Esta dupla crise, interna e externa, levou a uma profunda reformulação da política e ao surgimento da chamada "Total National Strategy". O conceito de "estratégia total” origina-se de um documento do Ministério da Defesa de 1977, mas somente foi posto em prática pela primeira vez no início dos anos 80, quando a política do "Constructive Engagement" do Presidente Reagan criou um ambiente mais favorável à coerção militar e econômica na África Austral. ${ }^{28}$

A chegada ao poder nos EUA de R. Reagan em janeiro de 1981, e o seu "Constructive Engagement” como "presente de casamento"29 para a África do Sul, foi pré-condição necessária para o pleno desdobramento da política sul-africana 
de guerras não-declaradas contra os seus vizinhos. Ao contrário do seu predecessor, J. Carter que, durante boa parte do seu governo seguiu uma abordagem regionalista em relação à África Austral, Ronald Reagan e seu Assistant Secretary for African Affairs, Chester Crocker, não só minimizaram a questão dos direitos humanos, mas também inseriram a política relativa ao sub-continente numa visão globalista de combate mundial ao comunismo. Nesta regressão ao fundamentalismo da Guerra Fria, as elites brancas da África do Sul gozaram, assim, de uma nova apreciação como co-combatentes no confronto global contra a União Soviética. O "Constructive Engagement”, que, através de um diálogo associado e construtivo com a minoria branca, deveria criar incentivos para a abertura e mudança democrática da África do Sul, articulou de facto uma postura passiva em relação ao apartheid e deu uma carte blanche para a política sul-africana de desestabilização dos países vizinhos. Regionalmente, como de facto permitiu a inserção coerciva sul-africana, inibiu assim uma solução dos conflitos inter-estatais por quase uma década. ${ }^{30} \mathrm{Em}$ Angola, pelo menos depois da revogação da Emenda de Clark em 1985, que proibia ajuda americana à UNITA, os Estados Unidos cooperaram no combate militar e terrorista do governo do MPLA e, assim, prolongaram durante muitos anos o sofrimento da população.

Sem a tácita tolerância dos EUA, que desde a metade dos anos 70 substituíram a Grã-Bretanha e Portugal como principal potência ocidental na região, e ainda sem o anti-comunismo firme e a predileção pela dominação branca ou governos africanos "moderados" da Primeira Ministra da Grã-Bretanha, M. Thatcher, a política sul-africana de "Total Strategy" não teria condições de ser realizada com tal amplitude. Dentro da percepção clássica de "zero-sum"31, o pensamento de "Estratégia Total” atribuiu todas as principais ameaças à segurança da África do Sul branca (o "encercamento" por Estados africanos radicais, as campanhas políticas e armadas da SWAPO e do CNA e a resistência popular interna) a um único fator: ao ataque total ("total onslaught") do marxismo e da União Soviética. Este "ataque total” teria que ser combatido com uma "estratégia total” (total strategy), interna e externamente. Na política regional, a total strategy combinou os seguintes elementos:

a) Desestabilização militar direta, através de intervenção em larga escala, combate às tropas regulares e ocupação de território sem formal declaração de guerra, como no caso de Angola. A retirada precipitada de Angola em 1976 não livrou o país da presença militar sul-africana. Desde 1976, a SADF e a força aérea realizaram ataques ao sul de Angola, contra, segundo se diz, alvos da SWAPO. Em novembro de 1979, escalaram os ataques terrestres, ocupando-se território ao sul do país e estabelecendo-se uma presença militar permanente nas Províncias de Cunene e Cuando Cubango. A partir destas áreas, intensificaram-se os ataques terrestres e aéreos contra cidades, infraestrutura e instalações militares angolanas. Por exemplo, entre janeiro e novembro de 1982, 53 ataques terrestres e mais do 
que 100 ataques aéreos foram computados. ${ }^{32}$ Em agosto de 1981, deu-se a, então, maior invasão, a chamada Operation Protea, usando mais do que 5.000 tropas terrestres. O exército angolano conseguiu parar o avanço somente em 110 quilômetros dentro do país. Como resultado, a maior parte da Província de Cunene ficou ocupada pelos sul-africanos até 1988. De lá, a SADF forneceu assistência maciça de combate à UNITA e realizou ataques aéreos ao norte.

b) Assistência aberta de combate a grupos anti-governamentais, como no caso da FNLA (1975) e da UNITA (apartir 1975) em Angola.

c) Assistência financeira e logística, no armamento e no treinamento, bem como a oferta do seu território nacional como área segura de retirada a guerrilheiros e terroristas que lutavam contra os governos dos Estados da Linha de Frente: UNITA em Angola, RENAMO ${ }^{33}$ em Moçambique, a milícia de Muzurewa e Sithole e os dissidentes da ZAPU em Zimbábue, a chamada Lesotho Liberation Army. Na maioria dos casos, as operações e até a existência destes grupos dependiam inteiramente do engajamento sul-africano.

d) Sabotagem a alvos econômicos e militares nos Estados da Linha de Frente, realizada por comandos sul-africanos. Estes atos de sabotagem eram inúmeros; a destruição de armazéns petrolíferos em Beira (Moçambique), freqüentes ataques a instalações militares e a destruição de grande quantidade de material, inclusive de uma grande parte da força aérea de Zimbábue, além dos diversos ataques às instalações petrolíferas de empresas norte-americanas em Cabinda (Angola), foram os mais espetaculares.

e) Coerção econômica contra aqueles Estados da Linha de Frente que eram dependentes da África do Sul e da sua rede de transporte, especialmente Zimbábue, Moçambique e Lesoto.

f) Envolvimento em golpes militares e tentativas de golpe, como no caso de Lesoto e das Seychelles.

g) A chamada "forward defense": ataques militares, assassinatos e atentados contra o CNA e a SWAPO, suas bases, escritórios, representantes e militantes comuns, e, também, contra campos de refugiados e membros da polícia e do militar local, simpáticos aos dois movimentos, em quase todos os Estados da Linha de Frente. ${ }^{34}$

Os objetivos principais da política sul-africana de desestabilização eram a “neutralização” dos Estados da Linha de Frente (com respeito à política e postura anti-apartheid) e a eliminação da ameaça à dominação branca, representada pelas atividades do CNA, da SWAPO e, em menor grau, do CPA (Congresso PanAfricano). A implementação desta estratégia transformou a década de 80 em um período de guerra não-declarada na África Austral e trouxe extrema insegurança e grande hostilidade às relações sub-regionais. As perdas humanas e materiais são estimadas em 1.500,000 mortos e US \$ 60 bilhões. Complementando as ofensivas militares, foi lançado um novo esquema de cooperação formal regional, a chamada 
“Constelação de Estados da África Austral” (CONSAS). A CONSAS representava mais uma tentativa por parte da África do Sul de explorar sua hegemonia econômica na região, aproveitando-se também do suposto medo dos governos africanos mais moderados perante o "comunismo", para construir um novo tipo de cordon sanitaire, desta vez, reunindo os últimos Estados com governo branco (Namíbia), Estados possivelmente moderados (o candidato à Presidência do Zimbábue, Bishoph Abel Muzorewa aprovou o esquema) e conservadores (Malawi), além dos BLSstates e os Bantutões. Mas, a recusa categórica mesmo daqueles Estados que dependiam economicamente da África do Sul, como os BLS-states, e a fundação da Southern African Development Coordination Conference (SADCC), em 1980, como contra-esquema de integração por parte dos Estados da Linha de Frente, rapidamente frustou o novo regionalismo dominado pela África do Sul. Com a SADCC, surgiu uma proposta de cooperação econômica que se dirigiu explicitamente contra a dominação econômica do sub-continente pela África do Sul, e cujos objetivos de cooperação e coordenação de desenvolvimento foram vistos como parte integral da luta contra o regime do apartheid.

A implementação da Total National Strategy como orientação política coerente é inseparável da ascensão de P.W. Botha ao poder como PrimeiroMinistro/Presidente e da centralização das decisões estratégicas nas mãos de uma pequena elite, predominantemente de militares, realizada sob seu governo. O próprio Botha foi instrumental na formulação da "estratégia total”, quando ainda era Ministro de Defesa em 1977. Elementos-chave desta "militarização"35 da política sulafricana são a elevação da South African Defence Force (SADF) da condição de instrumento de implementação de decisão para a de participante ativo no processo de formulação de política e, vinculado a isto, o surgimento do security establishment, dos "securocratas", no centro do poder no Estado. Claro vencedor desta transposição de poder foi o State Security Council (SCC), no qual os militares tinham controle, embora talvez não absoluto. Quem perdeu foi, especialmente, o tradicional locus de afrikaaner poder, o Partido Nacional, o Parlamento (branco) e aqueles ministérios que não estiveram tão estreitamente associados à opção militar nas arenas doméstica e regional. A burocracia diplomática, o Department of Foreign Affairs (DFA), foi um dos principais perdedores e ficou crescentemente marginalizado pelos "securocratas" na formulação e implementação da política exterior. Este processo já começou sob o governo de Vorster, com o crescimento em importância da agência de segurança (BOSS). ${ }^{36}$

Inicialmente, a política sul-africana de desestabilização obteve um sucesso impressionante. "South Africa's position as the dominant power in all of southern Africa increased dramatically”, argumenta R. Rotberg. "By mid-decade, South Africa had no local or global rivals for preeminence in the region south of Zaire and Tanzania. Despite its own profoundly unstable core, the extend of its newly accomplished hegemony had exceeded even the expectations of South Africa's 
most optimistic strategic planners." 37 Como consequência da desestabilização, a África do Sul teve condições de forçar os seus vizinhos a celebrar tratados de "não-agressão" com o regime de apartheid, nos quais os governos africanos se comprometeram a negar bases e outros auxílios para os movimentos de libertação (CNA e SWAPO), em troca da promessa sul-africana de terminar com as guerras não-declaradas (Acordo com Suazilândia de 1982, Acordo de Lusaka entre a África do Sul e Angola em 1984 e o mal-afamado Nkomati Accord do mesmo ano com Moçambique, que estava virtualmente à beira de um colapso em função do terrorismo de braço longo da África do Sul na forma da RENAMO. Mas esta humilhação dos movimentos de libertação e dos seus Estados vizinhos não inibiu a África do Sul a continuar com a desestabilização, mesmo contra Moçambique, violando sem escrúpulos os próprios tratados que foram celebrados com espetacular orgulho pela diplomacia sul-africana.

Foi, portanto, neste climax de hegemonia sul-africana na região na metade dos anos 80, que o terreno estava preparado para o colapso interno do sistema do apartheid e o fim da sua política regional agressiva. As razões complexas do desmoronamento do apartheid não podem aqui ser discutidas. ${ }^{38}$ Basta ressaltar que as repercussões da resistência interna (que ressurgiu depois de setembro de 1984 e que forçou o governo a declarar o Estado de Emergência em 1985), a decepção em relação à recusa do governo a realizar mudanças significantes na constituição (especialmente seguindo a famosa Rubicon Speech de Presidente P.W. Botha), interagiram com as conseqüências da transformação do ambiente internacional (fim da Guerra Fria), e com a postura mais determinada por parte das maiores sociedades ocidentais (elemento chave neste contexto foi a celebração do compreensivo Anti-Apartheid Act do Congresso Norte-Americano em 1986, que colocou os Estados Unidos no caminho de sanções, apesar da política conciliatória da Administração americana). ${ }^{39}$ Os distúrbios, que chegaram à beira de uma guerra civil, a retirada dos investimentos, especialmente por empresas americanas; sanções cada vez mais severas, e a perda de confiança na África do Sul por parte do mercado financeiro internacional, provocaram uma profunda crise interna que representa o background da saída do poder de P.W. Botha e da instalação de F.W. de Klerk como Presidente do Partido Nacional e do Estado sulafricano no final de 1989. Foi de Klerk quem percebeu que reformas fundamentais e até mesmo a abolição do regime do apartheid representavam a única saída para a África do Sul.

Na política regional, o início das mudanças ligeiramente antecede a posse de de Klerk, embora muitos observadores associem a transformação fundamental, isto é, o abandono por princípio da política de desestabilização, à de Klerk e à sua nova administração. O ponto de virada teria sido, nesta perspectiva, o famoso discurso no Parlamento no dia 2 de fevereiro de 1990, no qual de Klerk anunciou o fim do banimento dos grupos principais de oposição e a libertação de Nelson Mandela. ${ }^{40}$ 
A indicação mais visível das mudanças na política regional foram as negociações bem sucedidas em torno da independência de Namíbia e da retirada das tropas cubanas de Angola. Desde a formulação, em 1982, pela política americana, do linkage entre a independência de Namíbia e a presença dos Cubanos em Angola, estes dois conflitos eram ligados diplomática e politicamente (no campo de batalha, esta ligação existia desde 1975, com a invasão sul-africana de Angola). Durante os anos 80, este linkage servia para a África do Sul como mais um pretexto conveniente para sabotar as negociações sobre a Namíbia e terminar com a ilegal ocupação deste país, como foi prescrito pela Resolução 435 das Nações Unidas. A etapa decisiva para a solução do conflito começou no dia 5 de agosto de 1988, com a assinatura do Protocolo de Genebra, que estabeleceu um cessar-fogo entre os sul-africanos e angolanos em Angola e previu a retirada das tropas sulafricanas do território angolano. Já no dia 1 de setembro, este acordo foi implementado. Depois de uma série de negociações, o Acordo de Nova Iorque foi assinado entre Angola, África do Sul e Cuba (22.12.1988), estipulando os prazos para a retirada das tropas cubanas de Angola e da maioria das tropas sul-africanas da Namíbia, e, também, para a realização das eleições e da independência deste país. Em novembro de 1989, as eleições foram realizadas e, no dia 21 de março de 1990, a Namíbia conseguiu a sua independência sob o governo da SWAPO, tendo assim um final que a África do Sul durante tanto tempo havia considerado como um cenário inpensável. ${ }^{41}$

O que causou esta transformação dramática da política regional da África do Sul? Scholars identificam, via de regra, um conjunto de razões, embora com ênfase diferenciada acerca dos fatores individuais. ${ }^{42}$ No centro das explicações, encontra-se a transformação do ambiente internacional (o fim da Guerra Fria), e, como conseqüência, tanto o colapso da figura ideológica, que servia como justificativa para as agressões sul-africanas (o anti-comunismo), quanto as pressões das super-potências sobre os seus clientes no sentido de resolverem os conflitos regionais pacificamente. A transposição do poder militar no sul de Angola teria sido outro fator decisivo para a retirada sul-africana. O impacto causado pelo número elevado de soldados brancos mortos na guerra em Angola sob a sociedade branca sul-africana, as campanhas contra o serviço militar obrigatório e os imensos custos da guerra, num momento em que a África do Sul chegou a sofrer, crescentemente, sanções e vivia uma crise econômica, igualmente exerceram grande peso. Contribuiu, também, a ampla resistência de grande parte da sociedade namibiana contra a ocupação pela África do Sul. ${ }^{43}$

De importância central parece ter sido a derrota militar e as perdas significantes da África do Sul nas batalhas de Cuito Cuanavale em 1987-8 (o "Stalingrado da África do Sul”), a perda de superioridade aérea no sul de Angola e o avanço de tropas angolanas e cubanas até curta distância da fronteira entre Angola e Namíbia. Enquanto as operações anteriores em Angola foram de muito 
baixo risco, os confrontos que aconteceram entre a metade de 1987 e a primavera de 1988 mostraram uma guerra radicalmente transformada e os limites do poder militar sul-africano. Perante o enfraquecimento da opção militar, de um lado, o detente entre as super-potências, de outro, e com a necessidade de mostrar boa vontade junto à comunidade internacional para evitar sanções mais duras, a África do Sul optou trocar a independência da Namíbia pela retirada das tropas cubanas da África. Com esta troca, a África do Sul não perdeu a pose. Ao mesmo tempo, ela permitiu a Cuba celebrar o seu engajamento militar como fator decisivo na derrota da agressão do regime do apartheid em Angola e na proteção da "revolução angolana".44

A depreciação da opção militar em Angola (e, conseqüentemente, também na Namíbia) tiveram repercussões importantes para o processo político e decisório no governo da África do Sul. Os observadores perceberam um realinhamento de poder e influência, fortalecendo, ainda no governo Botha, os "pombas” e “diplomatas" em detrimento dos "securocratas". Tudo indica que, em termos de formulação da política externa, o DFA, com sua abordagem mais diplomática em relação às supostas ameaças de segurança, voltou à preeminência. Acompanhando a solução do conflito da Namíbia, o Presidente Botha iniciou uma nova iniciativa diplomática, com o fim de romper com o isolamento do seu país, visitando países europeus e africanos. Quando F.W. de Klerk assumiu o poder em 1989, completou esta tendência e depreciou o papel do State Security Council e do security establishment no processo de decisão do governo. ${ }^{45}$

Alguns analistas acadêmicos vêem a solução do conflito Namíbia/Angola e a nova ofensiva diplomática dentro de um contexto de uma mudança paradigmática mais profunda da política exterior sul-africana, reagindo, principalmente, ao fim da bipolaridade mundial e ao latente colapso da União Soviética. Esta "New Diplomacy" nasceu no último ano do governo Botha, ganhou enorme folêgo nos anos de transição entre 1990 e 1994 sob o comando de de Klerk, e se transformou, sem graves modificações, na principal orientação da política externa do Government of National Unity, liderado pelo CNA. ${ }^{46}$ Os princípios-chave da "New Diplomacy" foram primeiramente formulados em 1989 por Neil van Herden, Diretor Geral do MFA, o, então, mais senior diplomata sul-africano. ${ }^{47}$ Estes princípios destacam que a África do Sul deve fazer parte da África (e que não é uma extensão da Europa ao sul do globo), que problemas africanos devem ser resolvidos por africanos, que a África do Sul deve ser uma potência na região mas que seu poder tem limites, que ela depende de relações amigáveis com os seus vizinhos e que a sua política regional deve ser implementada com instrumentos não-coercivos. Ewans argumenta que a "New Diplomacy” não foi uma política regional nova e que ela representava mais uma mudança de estilo do que de substância. A noção da África do Sul como potência dominante permanecia intacta, só que a definição desta hegemonia mudou de "geo-política" para "geo-econômica" ${ }^{48}$ D. Venter, que 
identifica a mudança principal na política regional a partir do famoso discurso de de Klerk do dia 2 de fevereiro de 1990, sublinha, também, que esta nova diplomacia neo-realista se baseava no princípio de que a bandeira seguia o comércio e que a nova diplomacia visa a região como alvo da expansão econômica da África do Sul.. ${ }^{49}$

De qualquer forma, a "nova diplomacia” colocou um fim efetivo à política de desestabilização da "Total National Strategy”. A partir de 1989, o Estado sulafricano rapidamente se despediu dos instrumentos abertamente coercivos na política regional. Contudo, a continuação de ajuda para a UNITA e a RENAMO por parte do security establishment sul-africano sugere a pergunta, similar àquela a respeito da situação interna, se o Estado tinha uma dupla agenda na política regional ou se os militares conseguiram agir e realizar os seus próprios objetivos, sem o controle do Estado.

A "nova diplomacia” ganhou força com o fim do banimento das organizações da oposição e a libertação de Nelson Mandela e outros da prisão em fevereiro de 1990. O Presidente de Klerk e seu Ministro das Relações Exteriores, "Pik" Botha, iniciaram uma ofensiva diplomática, cujo objetivo era o retorno da África do Sul à comunidade internacional e o fim das sanções econômicas. Pelo menos a partir de fevereiro de 1991, a diplomacia sul-africana readquiriu a iniciativa em relação à questão das sanções. A "contra-política“ exterior do CNA, bem como da Organização da Unidade Africana (OAU) e dos Estados da Linha de Frente, perdeu o controle sobre este importante pilar da política internacional antiapartheid. ${ }^{50}$ Ainda na arena africana, a dupla de Klerk/Botha conquistou uma série de sucessos diplomáticos, na forma de tratados de cooperação e da iniciação, e, depois, da intensificação, de contatos econômicos, apesar da determinação de Nelson Mandela, em fazer valer, em vão, todo o seu prestígio político e moral, a fim de permitir a normalização das relações externas da África do Sul apenas depois da conclusão das negociações constitucionais. Na arena regional, a severa estiagem de 1992, que forçou muitos Estados do sub-continente a importar alimentos da África do Sul, ajudou de Klerk a romper o isolamento, mesmo no caso do "linha dura” Zimbábue.

Perante a perda do controle da inserção internacional da África do Sul, um assunto que a diplomacia do CNA conseguiu conquistar habilmente em torno dos anos 70 , e que permitiu ao movimento de libertação se projetar como um government-in-waiting ${ }^{51}$, o CNA, finalmente, desembarcou numa maior revisão na sua política exterior e "bowed to the inevitable.. and began the process of policy convergence with the New Diplomacy". ${ }^{2}$

Numa série de documentos políticos, o CNA reconheceu a mudança dramática no ambiente internacional, o colapso de seu velho aliado, a União Soviética, e o surgimento de uma nova ordem internacional multipolar, crescentemente dominada politicamente pelos Estados Unidos e que se baseia social e 
economicamente na hegemonia indisputada do sistema capitalista. No programa básico de governo de 1992 ("Ready to govern”), o CNA, e depois de 1994 também o novo DFA, adotaram a linguagem e os conceitos centrais da "New Diplomacy". ${ }^{3}$ Evans fala de um "pacto de elites" durante os anos de transição entre o DFA do governo branco e o Department of Foreign Affairs do CNA, e argumenta que "by the time of the elections in April 1994, in foreign policy terms at least, South Africa had become more or less a unitary state actor." 54

Mas este "pacto de elites" e as afinidades reveladoras na política exterior entre o governo de Klerk e do CNA não ficaram sem contestação. Na realidade, em vez de uma suave transição houve, desde 1990, um debate intenso sobre a direção da política externa, envolvendo acadêmicos, deputados e, também, o próprio CNA. Neste debate, o DFA foi criticado por parte dos acadêmicos e de membros da própria aliança do CNA, da COSATU, por não representar uma ruptura com o passado, nem em termos da composição do Ministério, nem em termos da maneira pela qual se deu a formulação da política exterior ("elitista, sem controle público“) e por aceitar, sem postura crítica, as regras do jogo internacional. A política exterior da "nova" África do Sul não constituía liderança moral no palco internacional e não enfrentava o “apartheid global”, isto é, a dominação do Sul pelo capitalismo mundial. ${ }^{55}$ Neste debate, tradições de política exterior bem distintas se confrontam dentro do CNA (por exemplo, entre os cadres que foram politizados dentro do país e aqueles que viveram no exílio) e entre o CNA e o tradicional foreign policy establishment. ${ }^{56} \mathrm{Em}$ termos ideológicos, a disputa aconteceu entre visões que propunham a aceitação das regras do sistema internacional e argumentavam em favor de uma inserção oportunista, inspirada por pura vantagem econômica, e aquelas que estavam dispostas a contestar as regras e praticar uma política exterior, baseada em firmes princípios morais e políticos. ${ }^{57}$

Mas, embora a execução da política exterior tenha sido claramente dominada pela visão neo-realista, pragmática e instrumentalista do de facto Ministro das Relações Exteriores e designado sucessor de Nelson Mandela como Presidente da África do Sul, Thabo Mbeki, estas disputas e a tensão entre um idealismo normativo de um lado, e Realpolitik de outro, causaram, junto com a fraqueza do atual Ministro, Alfred Nzo, problemas de orientação política e a ausência de um coerente perfil na política exterior, durante os primeiros três anos do novo Governo. ${ }^{58}$

De um lado, o Governo de União Nacional começou, especialmente em relação à região e ao continente africano, com uma cautelosa política de "baixo perfil”, que provocou severo ceticismo por parte daqueles africanos que esperavam da África do Sul um papel de liderança no continente. ${ }^{59}$ A OUA e o ex-Presidente da Tanzânia deram a advertência, que "if South Africa continues to hide behind the rhetoric of not wanting to play a leadership role, Africa would indeed suspect a hidden agenda." 60 O DFA justificou esta abordagem cautelosa como uma reação forte às políticas de dominação regional do passado: "Perhaps, initially, because of 
our past experience and fear of being accused of maintaining a big brother syndrome, we did not see ourselves as playing a leading role in the region.... Our perceived reluctance to have a 'hands on' approach to our region and to be pro-active in our continent has to some extent been viewed by our neighbors and friends with some suspicion and a great deal of cautions." 61

De outro lado, Nelson Mandela, repetidamente, surpreendeu o mundo com uma série de súbitas tentativas de mediação (nos conflitos do Zaire, Sudão, Timor Leste), sendo todas mal sucedidas, bem como com iniciativas de medidas relativas aos direitos humanos (no caso da Nigéria). Especialmente, a maneira pela qual foi conduzido o assunto nigeriano atrapalhou a comunidade internacional, em função do seu fulminante radicalismo moral não-realista e por suas mudanças de política abruptas. ${ }^{62}$ No palco mundial, parece que Mandela tenta balancear as relações excelentes com os EUA, de um lado, e compromissos e ligações com Estados amigos dos tempos da luta de libertação, que, atualmente, sofrem do ostracismo por parte dos Estados Unidos, de outro (Cuba, Irã, Líbia). ${ }^{63}$ Observadores ficam perplexos com a aparente contradição entre o alto rigor moral, articulado especialmente pelo próprio Mandela e, algumas vezes, o puro oportunismo econômico nas decisões da política exterior (por exemplo, no caso das exportações de armas ou no caso do reconhecimento da economicamente poderosa, mas nãodemocrática China Vermelha em vez de Taiwan). Recentemente, a disputa sobre a orientação na política exterior focaliza no significado de African renaissance, um termo que, depois de anos de pobreza conceitual, poderia emergir como uma nova palavra-chave nas relações internacionais sul-africanas. O "renascimento africano” significa a luta contra a marginalização internacional da África, para um novo poder político e econômico do continente, acompanhado pela democratização, respeito aos direitos humanos e combate à corrupção, uma luta na qual a África do Sul teria um papel chave. ${ }^{64}$ Mas, enquanto os "pragmáticos”, como Mbeki, vêem esta transformação do continente africano e a nova preeminência em aliança com o capital estrangeiro e sob as premissas de uma ordem mundial liberal e, ao final das contas, como uma oportunidade de vender mais produtos sul-africanos no continente, os seus críticos dentro do CNA falam do renascimento africano como um " sustained and vigilant challenge against the strategic orientation of globalization" e como um questionamento das "neo-colonial relations between Africa and the world's economic powers." 65

\section{III.}

Em relação à sub-região sul-africana, as declarações do CNA foram claras e consistentes. Em quase todos os documentos políticos foi atribuída à África e, especialmente, à SADCC e aos Estados vizinhos, alta prioridade nas relações internacionais da nova África do Sul. ${ }^{66}$ O documento de discussão sobre política 
exterior de 1993 enfaticamente destaca que "the region sustained us during the struggle and our destiny is intertwined with the region; our peoples belong with each other. Southern Africa is, therefore, a pillar upon which South Africa's foreign policy rests." ${ }^{67}$

Consciente das relações econômicas desiguais e exploradoras entre a África do Sul e o sub-continente, as declarações do CNA não deixaram dúvida de que o Estado pós-apartheid iria quebrar com esta assimetria e também com a "geopolítica” da era de Klerk. Os documentos de discussão de 1993 e 1994 formularam como objetivos básicos uma cooperação regional intensiva, a integração econômica da região e a "reconstrução" da África Austral depois do apartheid. A "nova ordem regional" se basearia em igualdade: "A democratic South Africa should therefore explicitly renounce all hegemonic ambitions in the region. It should resist all pressure to become the 'regional power' at the expense of the rest of the subcontinent; instead, it should seek to become part of a movement to create a new form of economic interaction in Southern Africa based on the principles of mutual benefit and interdependence.”68

Nelson Mandela fez grande esforço para acalmar o medo na região da predominância sul-africana depois do fim do apartheid: “...democratic South Africa will... resist any pressure or temptation to persue its own interests at the expense of the subcontinent. (...)... any move towards a common market or economic community must ensure that industrial development in the entire region is not prejudicated. It is essential therefore that a program to restructure regional economic relations after apartheid be carefully calibrated to avoid exacerbating inequalities.”69

Mas, em nenhum ramo da política exterior, a brecha entre princípios políticos e morais de um lado, e a realidade de outro, se tornou tão grande como na política regional. De fato, a nova África do Sul avançou em relação à "geo-economia” da era de Klerk, sem muita consideração aos interesses econômicos dos seus vizinhos. A ofensiva comercial da África do Sul na sub-região causou muita consternação nos Estados da SADC, especialmente em Zimbábue, cujas indústrias secundárias se sentiram expostas a uma concorrência desleal. Junto com a competição entre os Presidentes Mandela e Mugabe pela liderança política regional, o conflito comercial levou a tensões significantes entre os dois países.

Conflitos comerciais têm uma longa história na região, especialmente entre os dois países industrialmente mais avançados, a África do Sul e o Zimbábue. Desde a virada do século, as economias da sub-região são interligadas. Mesmo durante os anos de confrontação política e militar e de sanções contra a África do Sul, os produtos sul-africanos não desapareceram das pratileiras dos Estados vizinhos, embora os esforços da SADCC de diversificação tenham conseguido reduzir a sua presença substancialmente. Desde 1981, a exportação sul-africana para os mercados sub-regionais, fora da $\mathrm{SACU}^{70}$, diminuiu em volume e valor. ${ }^{71}$ Por exemplo, Zimbábue, o declarado “mercado natural” da África do Sul ao norte, 
conseguiu reduzir as suas importações da África do Sul de 27\% do total em 1981 para 19\% em 1991 e as exportações para a África do Sul de 21\% para 9\%. ${ }^{72}$

Depois da libertação de Nelson Mandela e do início das negociações constitucionais na África do Sul, isto é, bem antes das eleições de 1994, a África reabriu os seus mercados para produtos sul-africanos. A economia sul-africana, sofrendo da mais severa crise, com crescimento negativo como não se via há muitos anos e uma taxa de desemprego de cerca de 35\%, respondeu a esta oportunidade com alto vigor. ${ }^{73}$ Entre 1987 e 1995, as exportações da África do Sul para o resto da África subiram de 4\% (1987), 9,1\% (1992) para 13\% (1995) no total das exportações. ${ }^{74}$ A destinação principal deste comércio sul-africano é Zimbábue, cujo mercado chegou a ter a mesma importância para a África do Sul do que a Alemanha. Em Zimbábue, as importações sul-africanas pularam de 19\% do total em 1990 para 38\% em 1996, computando-se apenas o comércio legal. ${ }^{75}$

A presença comercial sul-africana se tornou altamente visível na vida cotidiana dos zimbabueanos: "Evidence of this new, skewed economic relationship with South Africa is found in every supermaket and mall in the more affluent areas of Zimbabwe's cities. First came the commodities which used to appear as regulars on shopping lists for visits south by middle-class Zimbabweans: Cape wines, imported whiskies, chocolate biscuits, VCRs and other 'luxury' items rarely found in Zimbabwe. Then came the whole store. In recent years there has been a proliferation of South African chains, like Nandos, Black Steer, Saddles and even an offshoot of the keg chain, which now litter the suburban landscape along with newly hatched local copycat enterprises offering big screen M-Net sports and canned-Castles imported from South Africa. More recently Clicks arrived on the scene, soon to be followed by Pick'n Pay."76

A África do Sul também retornou com muito êxito ao mercado moçambicano. Entre 1992 e 1994, as exportações sul-africanas para este país subiram em $42 \%$, fazendo de Moçambique o segundo mais importante parceiro comercial na África, fora da SACU. Além de trazer mercadoria, empresas sulafricanas ganharam também uma parcela significante da assistência financeira internacional, entrando no país para ajudar a reconstrução depois do fim da guerra civil. Empresas sul-africanas adquiriram amplos contratos para construção de estradas e pontes, reforma de aeroporto e eliminação de minas de guerra. ${ }^{77}$ Num certo sentido, a África do Sul aproveita-se agora dos efeitos das destruições que ela e seu cliente, a RENAMO, causaram durante os anos da política de desestabilização. Em outros países da África Austral, a mesma onda de mercadorias sul-africanas foi presenciada. ${ }^{78}$

A ofensiva comercial sul-africana não parou nos limites tradicionais da sub-região. Empresas mineiras da África do Sul estão ativas no Zaire/Congo, Burkina Faso, Guinea, Mali e outros países da África Ocidental. Empresas hoteleiras 
investem na África Oriental, e ferrovias e portos estão sendo construídos e reformados por sul-africanos no Zaire/Congo e Moçambique. ${ }^{79}$

Não há reciprocidade nesta explosão do export sul-africano. Pelo contrário, a África do Sul importa muito pouco dos seus parceiros comerciais africanos, resultando num alto superávit comercial em relação ao resto da África. A África do Sul exporta 50 vezes mais para Tanzânia, 39 vezes mais para Uganda e 20 vezes mais para o Quênia do que importa destes países. ${ }^{80}$ O déficit comercial de Zimbábue junto à África do Sul somou em quase US\$ 1 bilhão em 1995 (US\$ 1,253 bilhão de importação contra US\$ 266 milhões de exportação). ${ }^{81}$

Este déficit gigantesco entre os dois países não é resultado exclusivamente da economia pura e da "mão invisível” das forças de mercado. Ele é também, em parte, atribuível à política econômica regional da África do Sul, que combina a promoção e o incentivo à exportação (principalmente através do General Export Incentive Scheme) com certos elementos de proteção do mercado nacional. Paralelamente a esta política sul-africana, muitos países africanos, sob pressões do FMI e do Banco Mundial, estão liberalizando seus regimes de comércio e abrindo os seus mercados. Desta constelação, surgiram os conflitos comerciais, especialmente entre a África do Sul de um lado e os países industrialmente mais avançados da região de outro, mas, também, entre estes países. No caso da África do Sul e Zimbábue, este conflito chegou ser postulado como verdadeira "guerra comercial”.

A relação "sub-imperial” entre a África do Sul e o Zimbábue, e os resultantes conflitos, têm a sua origem nos tempos coloniais. O conflito emergiu quando o parceiro subalterno não mais aceitou inteiramente o seu "papel histórico" como mercado dos produtos sul-africanos e manifestou interesse próprio no desenvolvimento de uma indústria secundária, concretizada, no caso de Zimbábue, pela primeira vez na Grande Depressão dos anos 30. O resultado foram longas e polêmicas negociações que levaram à conclusão do Acordo Aduaneiro de 1935, que concedeu o acesso preferencial ao mercado sul-africano, sob um sistema de quotas, para certas categorias de produtos de Zimbábue (principalmente produtos agrícolas) em troca da concessão de tarifas aduaneiras preferenciais para produtos industrializados sul-africanos na entrada em Zimbábue.

Em 1964, um novo Preferential Trade Agreement foi concluído e renovado em 1969. A celebração deste acordo, junto com as repercussões das sanções internacionais contra Zimbábue, quando em 1965 os colonos brancos unilateralmente declararam a independência desta colônia britânica, sob o nome de Rodésia, fizeram com que o comércio entre a África do Sul e Zimbábue se intensificasse dramaticamente. Enquanto, em 1964, 23\% de todas as importações da Rodésia vinham da África do Sul, estas passaram a 55\% em 1969. ${ }^{82}$ Quando o governo da África do Sul cancelou o acordo em 1981, o que era legalmente possível, Zimbábue fez um grande esforço político e conseguiu negociar mais uma prorrogação. 
Um conflito comercial surgiu de novo, desta vez relativamente severo, quando o acordo aduaneiro de 1964 finalmente expirou em 1992. O governo sulafricano publicamente declarou a sua intenção de renegociar o acordo mas, na prática, empregou uma tática sutil, prolongando a renegociação, inibindo, assim, a conclusão de um novo acordo até o momento. Durante estes anos de utilização desta tática, interesses econômicos particulares e setoriais, isto é, dos empregadores e dos sindicatos sul-africanos, como por exemplo a Southern African Clothing and Textile Workers' Union, chegaram a influenciar substancialmente as negociações e, desta forma, a política regional da África do Sul. ${ }^{83}$ O resultado prático, e, provavelmente, a intenção, da prorrogação artificial das negociações por parte da África do Sul, foi um encarecimento do export zimbabueano, de facto um protecionismo contra uma variedade de produtos de Zimbábue, acima de tudo contra as exportações da indústria têxtil e de vestuário. Este de factoprotecionismo de um lado, e a ofensiva exportadora sul-africana de outro, provocaram bastante irritação e fizeram com que alguns zimbabueanos proclamassem que "President Nelson Mandela is doing more to hurt them now than apartheid ever did". 84

Desde setembro de 1991, as negociações do acordo comercial se arrastaram, chegando ao ponto de absoluto desânimo ao final de 1995. Anteriormente a esta data, empresas zimbabueanas já publicamente exigiram um protecionismo retaliatório contra as importações oriundas da África do Sul. ${ }^{85}$ O Presidente R. Mugabe também declarou que "time has come to protect our industries. We must act in defense. “86 Zimbábue e Zâmbia levantaram o assunto na $12^{\text {a }}$ reunião da cúpula da SADC em 1996, onde a África do Sul sofreu pesada crítica de vários países. ${ }^{87}$ Neste ponto, mesmo a Comunidade Européia comentou criticamente as políticas comerciais da África do Sul. ${ }^{88}$ Em julho de 1996, finalmente, o governo do Zimbábue chegou a ceder às pressões de certas frações do capital nacional e anunciou um novo regime de tarifas aduaneiras, que daria proteção alfandegária àqueles setores que mais tinham sofrido com a ofensiva comercial da África do Sul. ${ }^{89}$ Mas, embora oficialmente desmentida, a reação negativa por parte da África do Sul, da SADC (cuja política de integração prevê a realização de livre comércio entre os seus membros) e daquela parte da indústria do Zimbábue que não tem interesse em se confrontar com a África do Sul, deveria ter sido fulminante. Só alguns dias depois da publicação, o governo de Zimbábue cedeu às pressões e anunciou a suspensão das novas tarifas. ${ }^{90}$ Em fevereiro de 1997, mais uma vez, uma revisão do regime aduaneiro foi publicada, levando um certo grau de proteção para a indústria secundária nacional. ${ }^{91}$ Tudo leva a crer que a linha dura de Zimbábue e a ameaça de protecionismo tiveram sucesso. Logo depois do primeiro "tiro de aviso" em julho de 1996, as negociações sobre o comércio dos produtos têxteis foram concluídas e a África do Sul assinalou a sua disposição de apresentar uma solução para outras áreas sensíveis de comércio bilateral. ${ }^{92}$ Foi também obtido 
progresso no setor agrícola e, em agosto de 1997, o Memorandum of Understanding foi assinado neste sentido. ${ }^{93}$

A irritação dos Estados vizinhos em relação à política regional pós-apartheid da África do Sul agravou-se em função das dúvidas sobre o compromisso deste país com a integração regional. A postura da África do Sul frente a SADC, durante os primeiros dois anos do novo governo, caraterizou-se pelo mesmo baixo perfil que a sua política africana em geral. Em 1996, com a eleição de Nelson Mandela à Presidência da SADC, a África do Sul assumiu mais responsabilidade na Comunidade. Mesmo assim, ela se tornou um freio para a realização de mais integração formalizada entre os países da região. Somente com muita hesitação, este país assinou o Protocolo de Comércio de 1996, que prevê a realização de uma zona de livre comércio entre os membros da SADC, dentro de um período de oito a dez anos, e, até hoje, não o ratificou. ${ }^{94}$

Existe, também, um grande receio por parte dos países da SADC sobre as possíveis conseqüências de um tratado de livre comércio que está sendo negociado, aliás com muitas dificuldades, entre a Comunidade Européia (CE) e a África da Sul. Estas negociações começaram depois que a CE negou à África do Sul, obviamente sob fortes pressões dos agro-exportadores da Europa do Sul, a sua admissão na Convenção de Lomé. Em abril de 1997, a CE concedeu à África do Sul acesso qualificado na Convenção, o que traz certas vantagens, mas ainda lhe nega um acesso mais fácil junto ao mercado europeu como aquele que têm os outros países da ACP. Alguns países da SADC suspeitam que a África do Sul, em vez de se comprometer com os interesses da SADC e a estes dar prioridade, se aproveita da Comunidade para entrar na CE por esta "porta dos fundos". $95 \mathrm{O}$ multilateralismo aberto e ofensivo da África do Sul, e as tentativas de se aproximar de vários blocos econômicos (por exemplo, do Mercosul) reforçam a impressão de que não teria limitado as suas opções à SADC. Estas tensões entre a África do Sul e, especialmente, o Zimbábue sobre assuntos econômicos são agravadas por conflitos entre os Presidentes Mandela e Mugabe acerca da liderança política no sub-continente. Esta concorrência tem expressão mais concreta na disputa sobre as prerrogativas e a presidência do presumível poderoso órgão da SADC sobre política, defesa e segurança, que foi designado como sucessor da organização dos Estados da Linha de Frente. Embora oficialmente desmentido, tudo indica que Mandela, nesta disputa, teria ameaçado renunciar à SADC. ${ }^{96}$

Neste artigo, foi demonstrado que as relações regionais na África Austral sofreram uma mudança dramática que transformou esta região de conflito, a partir de 1989, em uma zona de relativa paz e segurança entre os Estados. O abandono da política sul-africana de desestabilização foi instrumental neste processo. Dentro do novo clima de paz e consenso político, surgiram outras fricções, principalmente de carácter econômico, que deixam a região pendular entre um grande compromisso para integração e “guerras comerciais”. De novo, a política regional da África do 
Sul foi o fator mais decisivo para o surgimento desta constelação. Ela oscila entre forte retórica moral e puro racionalismo econômico, extremos entre os quais a África do Sul ainda não encontrou um equilíbrio que pudesse satisfazer os seus vizinhos.

Junho de 1998

\section{Notas}

1 Territórios do Alto Comissário Britânico (British High Commissioner's Territories): Betsuanalândia (Botsuana), Suazilândia, Lesoto.

Sobre o expansionismo sul-africano histórico veja: HYAM, R.. The Failure of South African Expansion, 1908-1948. London: Macmillan, 1972, mas, também, com enfoque e interpretação diferente: CHANOCK, M.. Unconsummated Union: Britain, Rhodesia and South Africa, 1900-45. Manchester: Manchester UP, 1977.

Veja: HERBST, J.. "South Africa and Africa after Apartheid”. em: HARBESON, J.W. \& ROTHCHILD, D. (orgs.). Africa in World Politics. Post-Cold War Challenges. Boulder: Westview Press, 1995.

A Southern Africa Development Coordination Conference (SADCC) se transformou em Southern Africa Development Community (SADC) em 1992, assumindo um compromisso mais forte de integração regional. Atualmente 14 países fazem parte da Comunidade: Angola, Botsuana, Moçambique, Namíbia, Mauritius, República Democrática do Congo, Malawi, Seychelles, Tanzânia, Zâmbia, Zimbábue, Lesoto, Suazilândia, África do Sul.

5 ROTBERG, R.I.. "Introduction: South Africa the Region - Hegemony and Vulnerability". em: ROTBERG, R.I. (et. al.). South Africa and its Neighbors. Regional Security and Self-Interest. Lexinton: Mass. (Lexington Books). 1985. pp. 1.

THOMPSON, C.B.. “Zimbabwe in Sadcc: a Question of Dominance?” em: STONEMAN, C. (org.). Zimbabwe's Prospects. Issues of Race, State and Capital in Southern Africa. London: MacMillan, 1988. SHAW, T.M.. "Dependence or Interdependence in the Global Political Economy”. em: DELANCEY, M.W. (org.). Aspects of international relations in Africa. African Studies Programme, 1979, pp. 66.

7 SHAW, T.M.. "South Africa, Southern Africa and the World System”. em: CALLAGHY, Th. M. (org.). South Africa in Southern Africa, The Intensifying Vortex of Violence. New York: Praeger, 1983, pp. 45.

8 GRUNDY, K.W.. "Regional Relations in Southern Africa and the Global Economy”. em: DELANCEY, M.W.(org.). Aspects of international relations in Africa. African Studies Programme, 1979, pp. 90.

Para um discussão crítica acerca da viabilidade deste termo no contexto da África Austral como categoria analítica, veja: BLUMENFELD, J.. Economic Interdependence in Southern Africa from Conflict to Cooperation. London and New York: Pinter Publ. and St. Martin's Press for The Royal Institute of International Affairs, London, 1991. BUTLER, J.. "South Africa's Role in Southern Africa: An Historical Essay”. CALLAGHY, Th. M. (ed.). “South Africa in Southern Africa, The Intensifying Vortex of Violence”. New York: Praeger, 1983, pp. 21. BSL-states= Botsuana, Lesoto, Suazilândia.

11 A literatura acerca das relações econômicas entre a África do Sul e os seus países vizinhos, na dimensão histórica e atual, é muito ampla. Este artigo baseia-se principalmente nas seguintes publicações: HANLON, J.. Beggar your Neighbours: Apartheid Power in Southern Africa. 
Bloomington: Indiana Univ. Press, 1986. LEISTNER, E. e ESTERHUYSEN, P.. South Africa in Southern Africa: economic interaction. Pretoria: Africa Institute of South Africa, 1988. BLUMENFELD, J.. Economic Interdependence in Southern Africa - from Conflict to Cooperation. London and New York: Pinter Publ. and St. Martin's Press for The Royal Institute of International Affairs, London, 1991. ROTBERG, R.I. (et. al.). South Africa and its Neighbors. Regional Security and Self-Interest. Lexinton: Mass. (Lexington Books) 1985. CHAN, St. (org.). Exporting Apartheid. Foreign Policy in Southern Africa 1978-1988. London: Macmillan, 1990. CALLAGHY, Th. M. (org.). South Africa in Southern Africa, The Intensifying Vortex of Violence. New York: Praeger, 1983.

DU PISANI, A.. "South Africa and the region”. em: MILLS, G.(org.). From pariah to participant: South Africa's evolving foreign policy, 1990-1994. Johannesburg: SAIIA, 1994. p.52-69.

MILLS, G. \& BAYNHAM, S.. South African Foreign Policy, 1945-1990, em: MILLS, G. (org.). From pariah to participant: South Africa's evolving foreign relations, 1990-1994. Johannesburg: SAIIA, 1994, pp. 10.

15 Veja o compreensivo estudo de Barber e Barratt que interpreta a política exterior da África do Sul como ciclos de desafio e reação. BARBER, J. \& BARRATT, J.. South Africa's Foreign Policy. The search for status and security 1945-1988. Cambridge: CUP, 1990.

Veja: MILLS, G. \& BAYNHAM, S.. "South African Foreign Policy, 1945-1990”. em: MILLS, G. (org.). From pariah to participant: South Africa's evolving foreign relations, 1990-1994. Johannesburg: SAIIA, 1994. DU PISANI, A.. “South Africa and the region”. em: MILLS, G. (org.). From pariah to participant: South Africa's evolving foreign relations, 1990-1994. Johannesburg: SAIIA, 1994. pp. 52-69. BARBER, J. \& BARRATT, J.. South Africa's Foreign Policy. The search for status and security 1945-1988. Cambridge: CUP, 1990.

LEGUM, C.. Southern Africa. The Secret Diplomacy. London: Rex Collings, 1975, p.5.

18 Os Estados da Linha de Frente (Frontline States) consistiam em: Zimbábue, Angola, Botsuana, Moçambique, Tanzânia, Zâmbia. Em 1990, a Namíbia ingressou no grupo e, em 1994, a própria África do Sul.

LEGUM, C.. Southern Africa. The Secret Diplomacy. London: Rex Collings, 1975. LEGUM, C.. "Southern Africa: How the Search for Peaceful Change Failed”. em: LEGUM, C. (org.). Africa Contemporary Record 1975/76, London: Rex Collings, 1976.

20 STULTZ, N.H.. "South Africa in Angola and Namibia”. em: BLIGHT, J. \& WEISS, Th. G. (orgs.). The suffering grass: superpowers and regional conflict in southern Africa and the Caribbean. Boulder: Lynne Rienner, 1992, pp. 79.

FNLA= Frente Nacional de Libertação de Angola. UNITA= União Nacional para a Independência Total de Angola. MPLA= Movimento Popular de Libertação de Angola. Os três movimentos, que haviam lutado na guerra anti-colonial separadamente e em mútua competição, comprometeram-se com um procedimento para uma transição democrática e consensual no Acordo de Alvor de janeiro de 1995. Mas, especialmente a UNITA e a FNLA, não consideraram seriamente esta solução pacífica e buscaram o confronto militar contra o MPLA. Junto com a África do Sul, conseguiram fazer recuar o MPLA para Luanda e seus arredores, onde este movimento declarou a independência do país no dia 11 de novembro 1975. O governo do MPLA foi salvo da derrota militar pela maciça ajuda de combate por parte dos cubanos que, ao que parece, tomaram a iniciativa de responder positivamente aos pedidos do MPLA, sem consulta anterior à União Soviética. Veja: BLIGHT, J. \& WEISS, Th. G. (orgs.). The suffering grass: superpowers and regional conflict in southern Africa and the Caribbean. Boulder: Lynne Rienner, 1992. LAÏDI, Z.. "The Superpowers and Africa. the Constraints of a Rivalry, 1960-1990”. Chicago \& London: Chicago UP, 1990. 
23 STULTZ, N.H.. "South Africa in Angola and Namibia” em: BLIGHT, J. \& WEISS, Th. G. (orgs.). The suffering grass: superpowers and regional conflict in southern Africa and the Caribbean. Boulder: Lynne Rienner, 1992. GRUNDY, K. W.. The Militarization of South African Politics. Oxford: Oxford Univ. Press, 1988.

24 GRUNDY, K. W.. The Militarization of South African Politics. Oxford: Oxford Univ. Press, 1988, p. 90. SADF= South Africa Defence Force, o exército da África do Sul.

25 MARTE, L. F.: Political cycles in international relations: the cold war and Africa 1945-1990. Amsterdam: VU UP, 1994. p. 317.

26 MARTE, L. F.. Political cycles in international relations: the cold war and Africa 1945-1990. Amsterdam: VU UP, 1994, p. 317. LEGUM, C.. “Foreign Internvention in Angola”. em: LEGUM, C. (org.). Africa Contemporary Record 1975/76. London: Rex Collings, 1976, p. A31.

27 ZANU-PF= Zimbabwe African National Union-Patriotic Front. ZAPU= Zimbabwe African People's Union.

28 Este parte se baseia principalmente em: GRUNDY, K. W.. The Militarization of South African Politics. Oxford: Oxford Univ. Press, 1988, p. 90. WARDROP, J.. "Continuity and change in South Africa and in South Africa's relations with its neighbours”. em: BRUCE, R. D. (org.). Prospects for peace: changes in the Indian Ocean region. Perth: Indian Ocean Centre for Peace Studies, 1992, p. 253-272. SOMERVILLE, Keith. Foreign military intervention in Africa. London: Pinter, 1990, capítulo 6. STULTZ, N.H.. "South Africa in Angola and Namibia”. em: BLIGHT, J. \& WEISS, Th. G. (orgs.). The suffering grass: superpowers and regional conflict in southern Africa and the Caribbean. Boulder: Lynne Rienner, 1992. VENTER, D.. South Africa and the African comity of nations: from isolation to integration (= Africa Institute Research Paper $N^{0}$ 56). Pretoria: Africa Institute of South Africa, 1993. JOHNSON, PH. \& MARTIN, D. (orgs.). Destructive Engagement. Southern Africa at War. Harare: Zim Publish. House, 1986. HANLON, J.. Apartheid's Second Front: South Africa's War Against its Neighbours. Middlesex: Penguin Books, 1986. MILLS, G. \& BAYNHAM, S.. "South African Foreign Policy, 1945-1990”. em: MILLS, G. (org.). From pariah to participant: South Africa’s evolving foreign relations, 1990-1994. Johannesburg: SAIIA, 1994.

29 BLIGHT, J. \& WEISS, Th. G. (orgs.). The suffering grass: superpowers and regional conflict in southern Africa and the Caribbean. Boulder: Lynne Rienner, 1992, Conclusion, pp. 149.

WENZEL, Cl.. Die Südafrikapolitik der USA in der Ära Reagan. Konstruktives oder destruktives Engagement. Hamburg: Institut fur Afrikakunde, 1990. MARTE, L. F.. Political cycles in international relations: the cold war and Africa 1945-1990. Amsterdam: VU UP, 1994. LAÏDI, Z. The Superpowers and Africa. the Constraints of a Rivalry, 1960-1990. Chicago \& London: Chicago UP, 1990. COKER, C.. The United States and South Africa, 1968-1985: Constructive Engagement and its Critics. Durham: Duke Univ. Press, 1986. Mas, veja também Martin, que argumenta que a política norte-americana acerca da África Austral era mais diferenciada e tolerante do que a tese da "cruzada contra o comunismo" implica. MARTIN, B.. "American Policy Towards Southern Africa in the 1980s”. em: Journal of Modern African Studies, 27,1, pp. 23-46, 1989. Veja também: CROCKER, Ch.. High noon in Southern Africa. Making Peace in a Rough Neighborhood. New York \& London: W.W. Norton \& Co., 1992.

31 STULTZ, N.H. "South Africa in Angola and Namibia”. em: BLIGHT, J. \& WEISS, Th. G. (orgs.). The suffering grass: superpowers and regional conflict in southern Africa and the Caribbean. Boulder: Lynne Rienner, 1992.

32 HANLON, J.. Apartheid's Second Front: South Africa's War Against its Neighbours. Middlesex: Penguin Books, 1986, p. 159.

33 RENAMO= Resistência Nacional Moçambicana. Este grupo foi fundado pelo serviço secreto da Rodésia para ajudar o regime de Ian Smith na sua guerra contra os guerrilheiros da ZANU em Moçambique e contra o Estado moçambicano depois de 1975. Depois da independência da 
Rodésia/Zimbábue em 1980, a África do Sul assumiu a tutela sob este grupo e o reorganizou como um movimento terrorista eficaz e na sua arma principal para a desestabilização do governo moçambicano. $\mathrm{O}$ terrorismo da RENAMO levou Moçambique à beira de um colapso. Porém, esta oposição armada contra o Estado moçambicano não reflete só as maquinações da África do Sul. A RENAMO conseguiu, também, se aproveitar das divisões na sociedade moçambicana (étnicas, regionais, sociais), do neo-tradicionalismo, da distância dos chefes tradicionais junto ao Estado e da rejeição da política de modernização e do “jacobinismo” das elites urbanas e socialistas pela sociedade rural. Todavia, entre os pesquisadores, bem como no debate público em Moçambique, a relevância destas raízes locais e, com isso, das razões locais da revolta, estão sujeitas a severas disputas. Nas eleições de 1994, a RENAMO conseguiu 38\% dos votos, o seu candidato à Presidência, Dhlakama, 33,7\%. A votação reflete uma clara polarização étnica/regional. Para o debate sobre o caráter da RENAMO veja: MINTER, W.. “Apartheid's Contras: An Inquiry into the Roots of War in Angola e Mozambique”. Johannesburg \& London: Zed, 1996. VINES, A.. Renamo: Terrorism in Mozambique. Centre for Southern African Studies, University of York, London/Bloomington/Indianapolis: James Currey/Indiana University Press, 1991. YOUNG, Tom. “The MNR/RENAMO: External and Internal Dynamics”. em: African Affairs. 1990, pp. 490-509.

34 HANLON, J.. Apartheid's Second Front: South Africa's War Against its Neighbours. Middlesex: Penguin Books, 1986. DAVIES, R. und O’MEARA, D.. “Total Strategy in Southern Africa An Analysis of South African Regional Policy since 1978”. Em: CHAN, St. (org.). Exporting Apartheid. Foreign Policy in Southern Africa 1978-1988. London: Macmillan, 1990. pp. 179. GRUNDY, K. W.. The Militarization of South African Politics. Oxford: Oxford Univ. Press, 1988.

36 ibid., p. 88.

ROTBERG, R.I.. "Introduction: South Africa in the Region - Hegemony and Vulnerability”. em: ROTBERG, R.I. (et. al.). South Africa and its Neighbors. Regional Security and SelfInterest. Lexinton: Mass. (Lexington Books), 1985. pp. 1.

38 Como introdução veja: SPARKS, A.: "Tomorrow is Another Country. The Inside Story of South Africa's Negociated Revolution”. South Africa: Struik Book Distributors, 1994. BEINART, W.. Twentieth Century South Africa. Oxford: OUP, 1994.

WENZEL, Cl.. Die Südafrikapolitik der USA in der Ära Reagan. Konstruktives oder destruktives Engagement. Hamburg: Institut fur Afrikakunde, 1990.

40 VENTER, D.. South Africa and the African comity of nations: from isolation to integration (= Africa Institute Research Paper No 56). Pretoria: Africa Institute of South Africa, 1993.

41 Para o conflito de Namíbia e a sua solução veja: PYCROFT. “Angola - 'The Forgotten Tragedy””. em: Journal of Southern African Studies, vol. 20, N² 2, 1994, pp. 241. WOOD, B.. "Preventing the Vacuum: Determinants of the Namibian Settlement”. em: Journal of Southern African Studies, vol. 17, № 2, 1991. HOFMEIER, R. (org.). Afrika Jahrbuch (1987-1996). Politik, Wirtschaft und Gesellschaft in Afrika südlich der Sahara. Opladen: Leske \& Budrich, 19881997.

Veja entre outros: HOFMEIER, R. (org.). Afrika Jahrbuch. Politik, Wirtschaft und Gesellschaft in Afrika südlich der Sahara. Opladen: Leske \& Budrich, 1988. MARTE, L. F.. Political cycles in international relations: the cold war and Africa 1945-1990. Amsterdam: VU UP, 1994. TVEDTEN, I.. “US policy toward Angola since 1975”. Journal of Modern African studies, 30, 1, p.31-52, 1992. SOMERVILLE, Keith. Foreign military intervention in Africa. London: Pinter, 1990. WARDROP, J.. "Continuity and change in South Africa and in South Africa's relations with its neighbours”. em: BRUCE, R. D. (org.). Prospects for peace: changes in the Indian Ocean region. Perth: Indian Ocean Centre for Peace Studies, pp. 253-272, 1992.

Esta análise se baseia principalmente em: WOOD, B.. "Preventing the Vacuum: Determinants of the Namibian Settlement”. em: Journal of Southern African Studies, vol. 17, № 2, 1991. 
44 Blight e Weiss citam uma entrevista com Jorge Risquet, membro do Politbureau cubano e principal negociador dos acordos com a África do Sul: "Cuito Cuanavale was decisive. the negociations came later. The battle of Stalingrad took place three years before the fall of Berlin, but it was at Stalingrad that the outcome of World War II was decided.... The South Africans realized that putting up a frontal battle in southern Angola and northern Namibia would amond to the swan song of apartheid. So they decided to concede Namibia.” BLIGHT, J. \& WEISS, TH. G. (orgs.). The suffering grass: superpowers and regional conflict in southern Africa and the Caribbean. Boulder: Lynne Rienner, 1992: “Conclusions: Must the Grass Suffer?”, p. 161. Veja também: O’NEILL, K. \& MUNSLOW, B.. “Angola: Ending the Cold War in Southern Africa”. em: FURLEY, O. (org.). Conflict in Africa. "London: Tauris, 1995, pp. 183. OHLSON, Th.. "The Cuito Cuanavale Syndrome: Revealing SADF Vulnerabilities”. em: MOSS, G. \& OBERY, I. (orgs.). South African Review 5. Johannesburg: Ravan, 1989, pp. 181.

WARDROP, J.. "Continuity and change in South Africa and in South Africa's relations with its neighbours”. em: BRUCE, R. D. (org.). Prospects for peace: changes in the Indian Ocean region. Perth: Indian Ocean Centre for Peace Studies, pp. 253-272, 1992.

Para o argumento da continuidade na política exterior da África do sul a partir da "New Diplomacy“ de van Heeren, veja: EVANS, G. "South Africa in Remission: the Foreign Policy of an Altered State”. em: Journal of Modern African Studies, 34,2, pp. 249-269, 1996. Veja também: VALE, P.. “South Africa’s “New Diplomacy””. em: MOSS, G. \& OBERY, I. (orgs.). South African Review 6. From "Red Friday” to Codesa. Johannesburg: Ravan, 1992, pp. 424. VAN HEERDEN, N.P.. "South Africa and Africa: The New Diplomacy”. em: ISSUP Bulletin, No. 4, pp. 1-11, 1989. Ibid.

VENTER, D.. South Africa and the African comity of nations: from isolation to integration (= Africa Institute Research Paper $N^{\circ}$ 56). Pretoria: Africa Institute of South Africa, 1993. DU PISANI, A.. "South Africa and the region”. em: MILLS, G. (org.). From pariah to participant: South Africa's evolving foreign relations, 1990-1994. Johannesburg: SAIIA, 1994. p.52-69.

Veja: HOFMEIER, R. (org.). Afrika Jahrbuch. Politik, Wirtschaft und Gesellschaft in Afrika südlich der Sahara. Opladen: Leske \& Budrich, 1990 e 1991. The Financial Times, 7.5.1991: "On the road to normalization”. Die Welt (Hamburg), 17.4.1991: “Geteiltes Echo am Kap auf EG-Entscheidung”.

51 EVANS, G. "South Africa in Remission: the Foreign Policy of an Altered State". Journal of Modern African Studies, 34,2, pp. 249-269, 1996. THOMAS, S.. The Diplomacy of Liberation: the international relations of the African National Congress of South Africa, 1960-1985. London: 1995. JOHNSTONE, A. und SHEZI, S.. "The ANC's foreign policy”. JOHNSTONE, et.al. (orgs.). Constitution-Making in the new South Africa. London: Leicester UP, 1993.

52 EVANS, G.. "South Africa in Remission: the Foreign Policy of an Altered State”. Journal of Modern African Studies, 34,2, 1996, p. 258.

53 AFRICAN NATIONAL CONGRESS. Ready to Govern. ANC policy guidelines for a democratic South Africa adopted at the National Conference (28-31.5.1992), 1992. AFRICAN NATIONAL CONGRESS. Foreign Policy in a New Democratic South Africa. A Discussion Paper (Oct. 1993), 1993. AFRICAN NATIONAL CONGRESS. Discussion Paper: Foreign Policy Perspective in a Democratic South Africa (Dec. 1994), 1994. DEPARTMENT OF FOREIGN AFFAIRS (DFA). South African Foreign Policy, Discussion Document, Julho, 1996. DFA. Parliamentary Briefing, Sept. 1997. DFA. Statement on Nzo's Budget Speech, 7/5/ 98.

EVANS, G.. "South Africa in Remission: the Foreign Policy of an Altered State”., Journal of Modern African Studies, 34,2, 1996, p. 259 \& p. 266.

55 Mail and Guardian, 9.6.1995: "Foreign Affairs Department Under Fire”. Mail and Guardian, 8.9.1995: "The Realists in a Tussle with Radicals". 
HOFMEIER, R. (org.). Afrika Jahrbuch. Politik, Wirtschaft und Gesellschaft in Afrika südlich der Sahara. Opladen: Leske \& Budrich, 1995.

HOFMEIER, R. (org.). Afrika Jahrbuch. Politik, Wirtschaft und Gesellschaft in Afrika südlich der Sahara. Opladen: Leske \& Budrich, 1995. EVANS, G.. "South Africa in Remission: the Foreign Policy of an Altered State”. Journal of Modern African Studies, 34,2, 1996. SHUBIN, Vladimir: Flinging the Doors Open: Foerign Policy of the New South Africa. CASA. Uni of Western Cape, Working Paper. Bellville: CSAS, 1995. CALLAND, R. e WELD, D.. Multilateralism, southern Africa and the postmodern world: an exploratory essay. Bellville: University of the Western Cape, Centre for Southern African Studies, 1994.

HOFMEIER, R. (org.). Afrika Jahrbuch. Politik, Wirtschaft und Gesellschaft in Afrika südlich der Sahara. Opladen: Leske \& Budrich, 1995. The Star (Johannesburg), 31.5.1995: "Foreign Policy: just a set of impulses?“.

Le Monde (Paris), 6.11.1996: "La grande prudence de la diplomatique sud-africaine”. Das Parlament (Bonn), 21.2.1997: “Vom internationalen Paria zum überforderten Hoffnungsträger”. The Star, Johannesburg, 1996, 25.9.: “African renaissance can’t remain romantic concept". DFA. Background Document delivered by the MFA at the Parliamentary Media Briefing Week, $11 / 2 / 1997$

The East African (Nairobi), 4.8.97: "Big Shift as Mandela Warms up to Abacha. Frankfurter Rundschau, 14.4.1996: "Ein Neuling, der in viele Fettnapfchen tritt.”

Financial Times (London), 3.10.1996: "Tricky balancing act. Policy makers are having to contend with the legacy of apartheid and old friendships". Frankfurter Rundschau, 22.10.1997: "Die USA suchten Mandela zu besänftigen”.

O Presidente Mandela, em um discurso no Parlamento do Zimbábue, explica, assim, a "African renaissance": "The time has come for Africa to take full responsibility for her woes and use the immense collective wisdom it possesses to make reality of the idea of the African renaissance. It is a renaissance that must mean that Africa refuses to be a passive onlooker in a chinging world, hapless victim to modern machinations by the forces historically responsible for her woes. Only this way can Africa assert her right to be an equal partner in world affairs.” Em: The Herald (Harare), 21.5.1997: “Africa must take responsibility for its woes - Mandela”.

ANC Discussion Paper. Developing a Strategic Perspective on South Africa Foreign Policy, July 1997. Veja também: Financial Times (London), 22.10.1997: "Reborn Africa reaches out. Ideological battles between the old left and the pragmatists persist in the ANC".

AFRICAN NATIONAL CONGRESS. Ready to Govern. ANC policy guidelines for a democratic South Africa adopted at the National Conference (28-31.5.1992), 1992. AFRICAN NATIONAL CONGRESS. Foreign Policy in a New Democratic South Africa. A Discussion Paper (out. 1993), 1993. AFRICAN NATIONAL CONGRESS. Discussion Paper: Foreign Policy Perspective in a Democratic South Africa (dec. 1994), 1994. DFA. South African Foreign Policy. Discussion Document, julho 1996. DFA. Parliamentary Briefing, set. 1997. ANC. Discussion Paper: Developing a Strategic Perspective on South Africa Foreign Policy, julho 1997.

ANC. Foreign Policy in a New Democratic South Africa. A Discussion Paper (out. 1993), 1993.

Ibid.

69 Nelson Mandela: “South Africa’s Future Foreign Policy”. em: Foreign Affairs 72, nov. - dec. 1993, pp. 91-2.

70 SACU= Southern African Customs Union. União aduaneira entre a África do Sul, Botsuana, Lesoto e Suazilândia que existe desde o início do século XX. Depois da sua independência, a Namíbia se integrou a esta União.

MAASDORP, G.G.. "Squaring up to Economic Dominance: Regional Patterns”. em: ROTBERG, R.I., et. al.; South Africa and its Neighbors, pp. 91, 1985. 
72 ENGEL, U.. The Foreign Policy of Zimbabwe. Hamburg: Institut für Afrikakunde, 1994, p. 291.

73 KAPLINSKY, R.. “The Manufacturing Sector”. em: MAASDORP, G. e WHITESIDE, A.. Towards a Post-Apartheid Future. Political and Economic Relations in Southern Africa. London/ Basingstoke: MacMillan, 1992, pp. 83. The Star, Johannesburg, 1996, 19.6.: “Unemployment resists feeble assaults“.

Financial Mail, Johannesburg, 1992, 28.8.: "Trade. New directions“. The East African, Nairobi, 1995, 24.7.: "S. African firms fill void as West turns elsewhere“. PIAZOLO, M.. "Südafrika - Wachstumsmotor der südlichen Afrika?” em: Afrika Spektrum, 31, Jg., 96/3, Hamburgo, 1996. INTERNATIONAL MONETARY FUND. Direction of Trade Statistics Yearbook 1997. Washington: 1997, pp. 404-5.

Mail \& Guardian, 1997, 23. - 29.5.: "South Africa accused of bully-boy tactics in trade with Zimbabwe.“

Ibid.

The Business Herald, Harare, 1993, 3.6.: "Pretoria seeks to boost trade with Mozambique“. The Star, Johannesburg, 1994, 24.11.: "Trade boom for SA goods“.

The Star, Johannesburg, 1994, 24.11.: "Trade boom for SA goods“. Mail \& Guardian, Johannesburg, 1996, 7.6.: "Zim attacks SA on Trade policies. “ The Star, Johannesburg, 1996, 14.4.: "Export drive causes havoc for African neighbours".

The East African, Nairobi, 1995, 24.7.: "S. African firms fill void as West turns elsewhere“. The Star, Johannesburg, 1996, 14.4.: "Export drive causes havoc for African neighbours“.

INTERNATIONAL MONETARY FUND. Direction of Trade Statistics Yearbook 1997. Washington: 1997, pp. 404-5. The Herald, Harare, 1996, 24.5.: "President tells SA to cooperate“. The Herald, Harare, 1997, 8.3.: "Trade deal will see beef exports to SA“.

BARBER, J. \& BARRAT, J.. South Africa's Foreign Policy. The Search for Status and Security 1945-1988, p.133.

83 Financial Gazette, Harare, 1993, 4.3.: "Textile barons hold key to SA trade talks". The Herald, Harare, 1996, 21.2.: "South African trade unions protest against textil imports".

Mail \& Guardian, Johannesburg, 1996, 7.6.: “Zim attacks SA on Trade policies”. Financial Gazette, Harare, 1995, 13.7.: "Retaliatory tariffs urged against AS”.

The Herald, Harare, 1996, 24.5.: "President tells SA to co-operate".

The Sunday Mail, Harare, 1996, 4.2.: "SA under fire at SADC conference".

89 The Herald, Harare, 1996, 5.6.: "View SADC with a soft heart, SA told".

The Star, Johannesburg, 1996, 3.7.: "SA-Zimbabwe trade war looms”. The Herald, Harare, 1996, 2?.7.: "New tariffs announced to protect goods from external competition".

90 The Herald, Harare, 1996, 27.7.: "New tariffs suspended pending consultations".

91 The Herald, Harare, 1997, 15.2.: "State announces new tariff structure”. The Business Herald, Harare, 1997, 20.2.: "New tariffs bring mixed blessings".

92 The Herald, Harare, 1996, ?.8.: "At last SA agrees to cut tariffs. Thousands of local textile jobs now safe”. The Herald, Harare, 1996, 8.8.: "Details on deal with SA". The Herald, Harare, 1996, ?.10.: „Zimb, SA agree to speed up trade talks”. The Herald, Harare, 1996, 8.10.: “SA committed to trade deal”.

93 Financial Gazette, Harare, 1997, 6.3.: "SA offer raises hop for stalled trade talks". The Herald, Harare, 1997, 8.3.: “Trade deal will see beef exports to SA”. The Herald, Harare, 1997, 6.8.

94 SADC. Protocol on Trade in the Southern African Development Community, 1996. The Star (Johannesburg), 2.7.1997: "Problems of past haunt region”.

95 Electronic Mail \& Guardian (Johannesburg), 24.11.1997: "SA's neigbours wary of an EU trade deal.” Veja também: HOLLAND, M.: "South Africa, SADC, and the European Union: Matching Bilateral with Regional Policies”. em: Journal of Modern African Studies, 33, 2, 1995, pp. 263-283. 
96 The Financial Gazette, Harare, 11.9.1997: “Major power struggle rocks SADC leadership”. The Independent, Harare, 19.9.1997: “Mandela refutes threat to quit SADC”.

Resumo

O artigo demonstra que as relações regionais na África Austral sofreram uma mudança dramática que transformou esta região de conflito, a partir de 1989, em uma zona de relativa paz e segurança entre os Estados. O abandono da política sul-africana de desestabilização foi instrumental neste processo. Dentro do novo clima de paz e consenso político, surgiram outras friç̧ões, principalmente de carácter econômico, que deixam a região pendular entre um grande compromisso para integração e “guerras comerciais”. De novo, a política regional da África do Sul é o fator decisivo para o surgimento desta constelação. Ela oscila entre forte retórica moral e puro racionalismo econômico.

\section{Abstract}

The article demonstrates that the regional relations in the Southern Africa experienced a dramatic change which transformed this conflict region, after 1989, into a relative peaceful and safe zone between states. The abandonment of South Africa destabilization policy was instrumental in the process. Inside this new atmosphere of peace and political consensus other friction, mainly economic ones, rose and make the region oscillate between a great commitment with integration and "commercial wars". Again, South Africa regional policy is decisive for the rising of this constellation. It oscillates between a strong moral rhetoric and a pure economic ratio.

Palavras-chave: África do Sul. Sub-continente sul-africano. Política regional. Key-words: South Africa. South-African sub-continent. Regional policy. 